\title{
A Convenient, NMR-Based Method for the Analysis of Diastereomeric Mixtures of Pseudoephedrine Amides
}

\author{
William J. Chain and Andrew G. Myers*
}

\section{Supporting Information}

Index:

1H NMR Spectra for 52 Different Oxazolium Triflate Derivatives Formed by

Cyclization of Pseudoephedrine Amides with Triflic Anhydride-Pyridine 

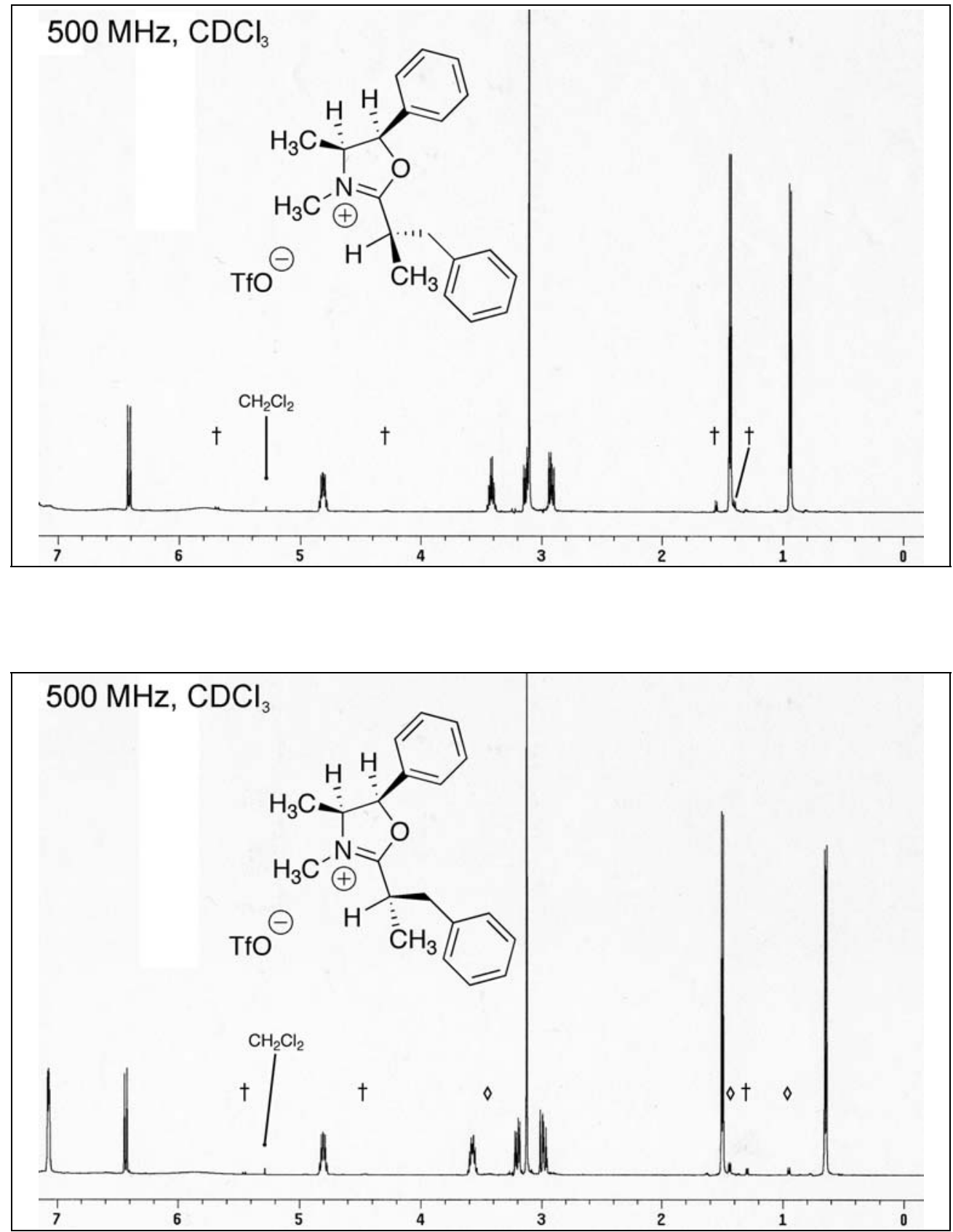
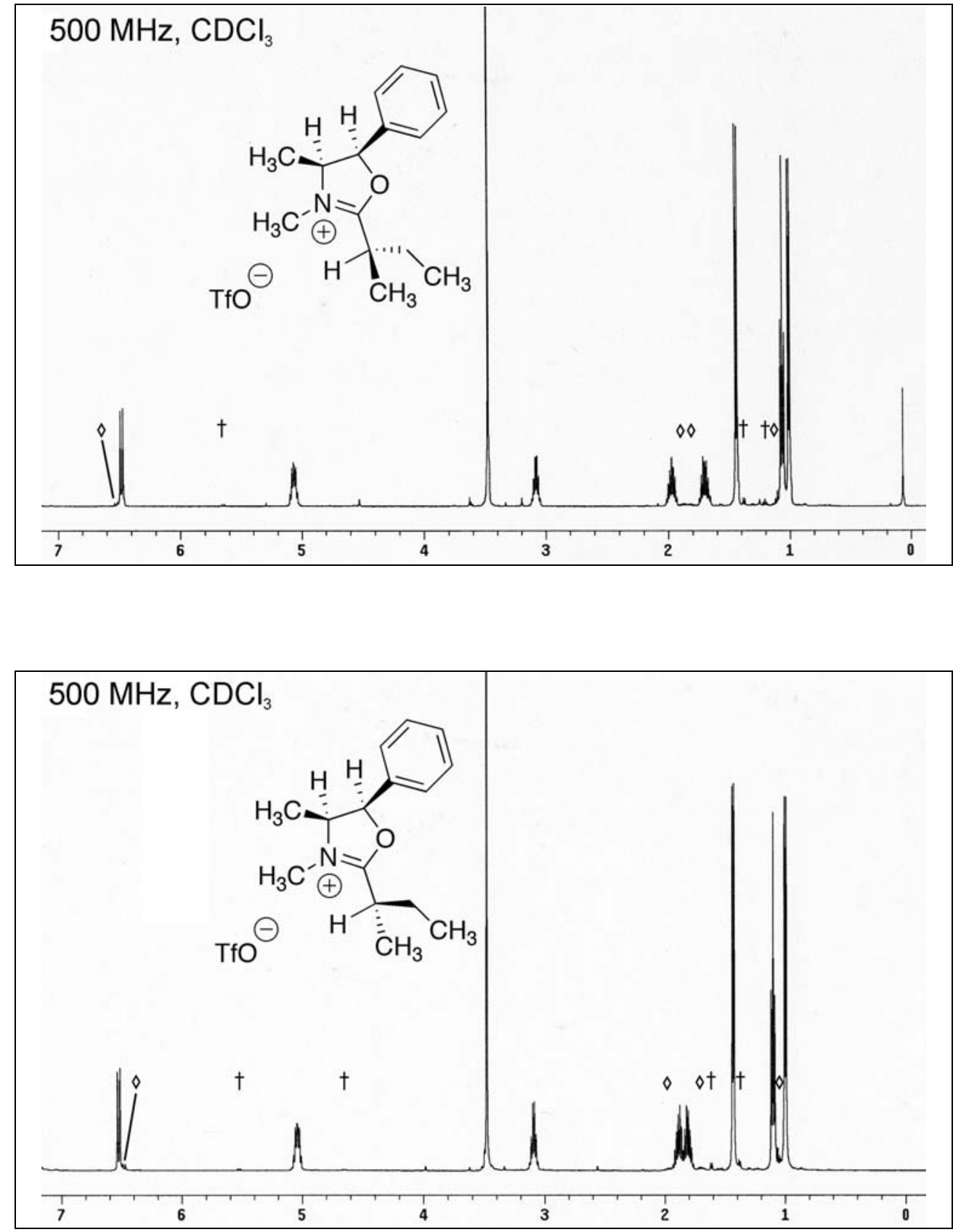

S2 

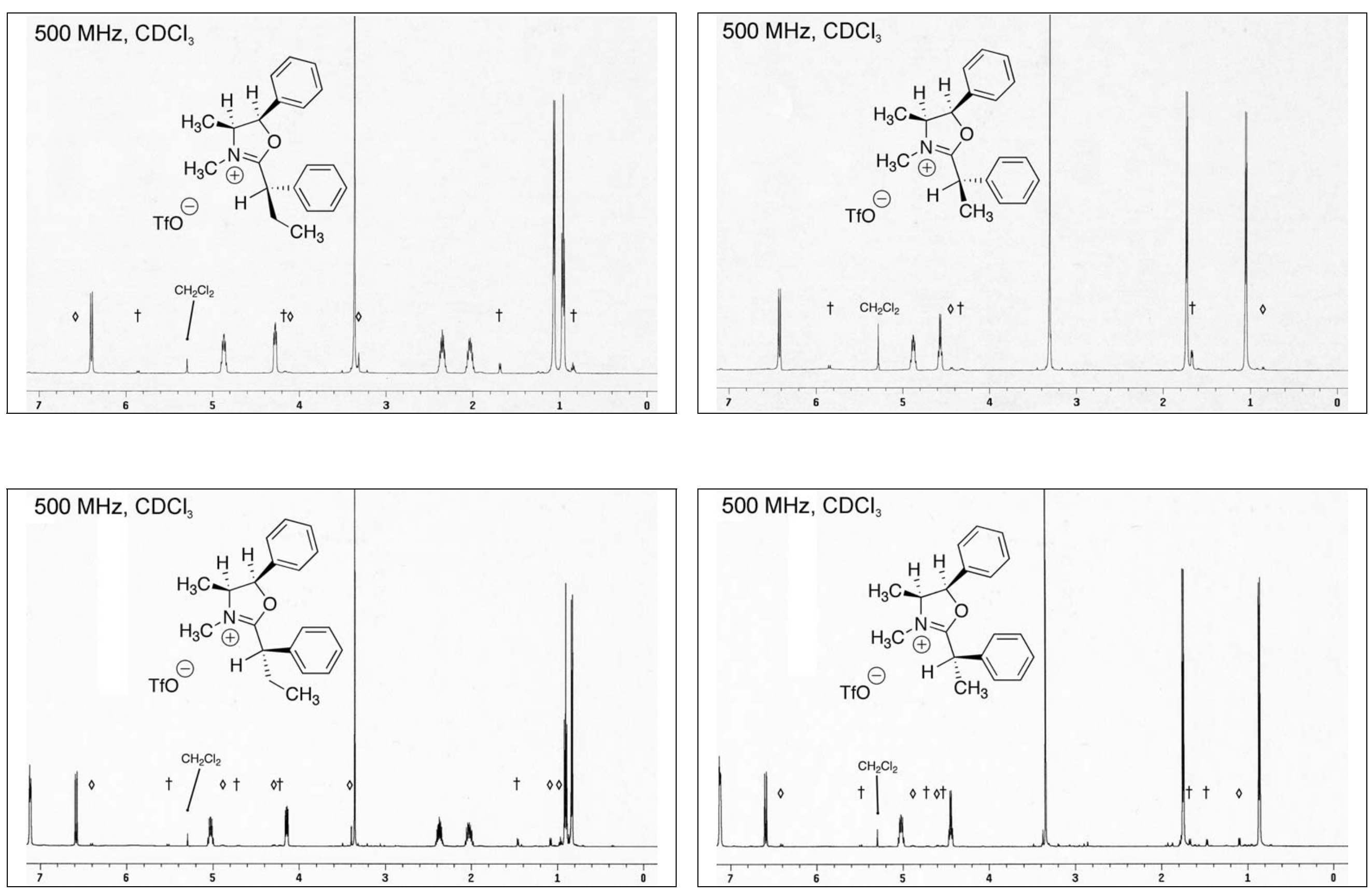

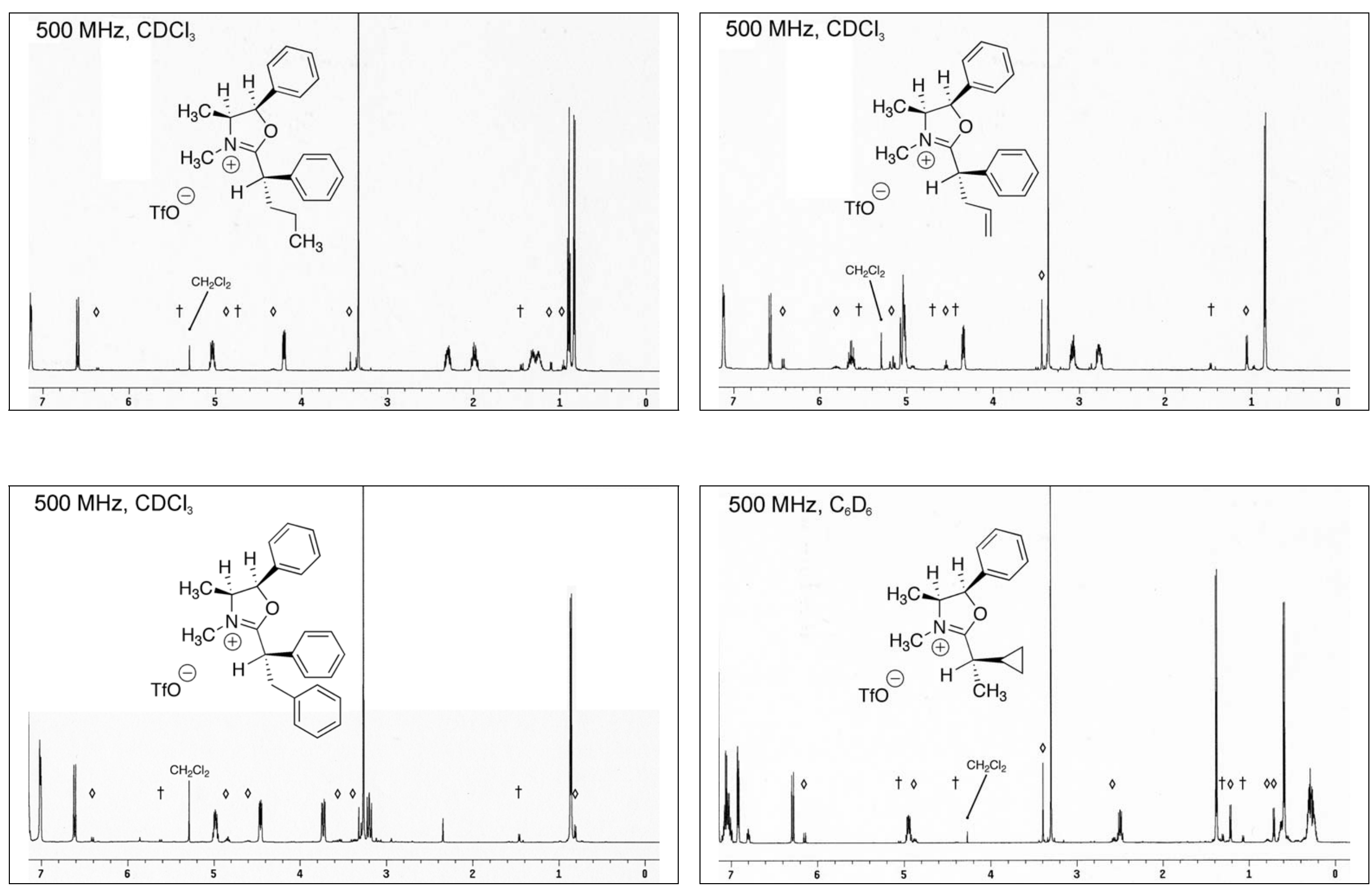

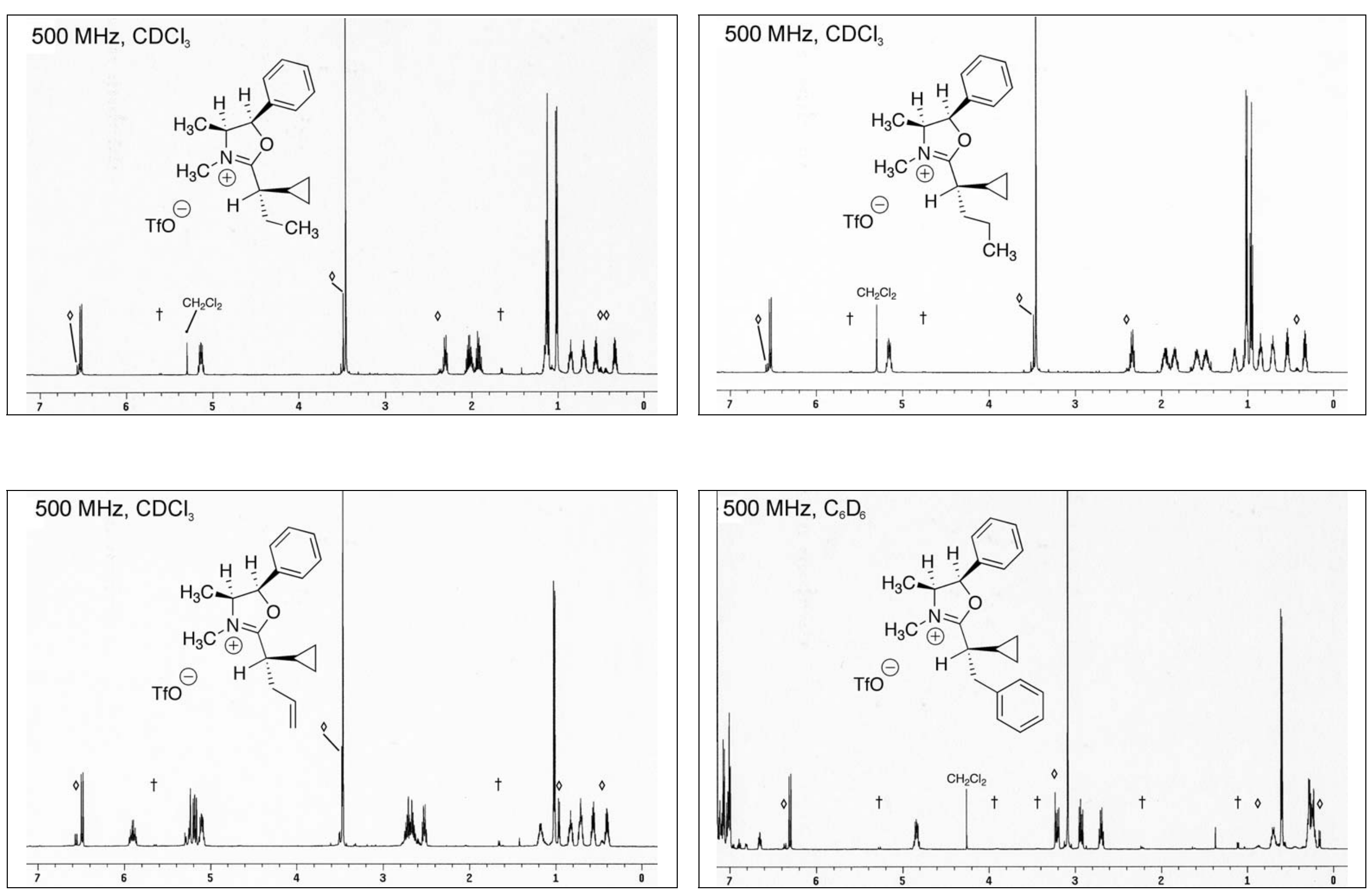

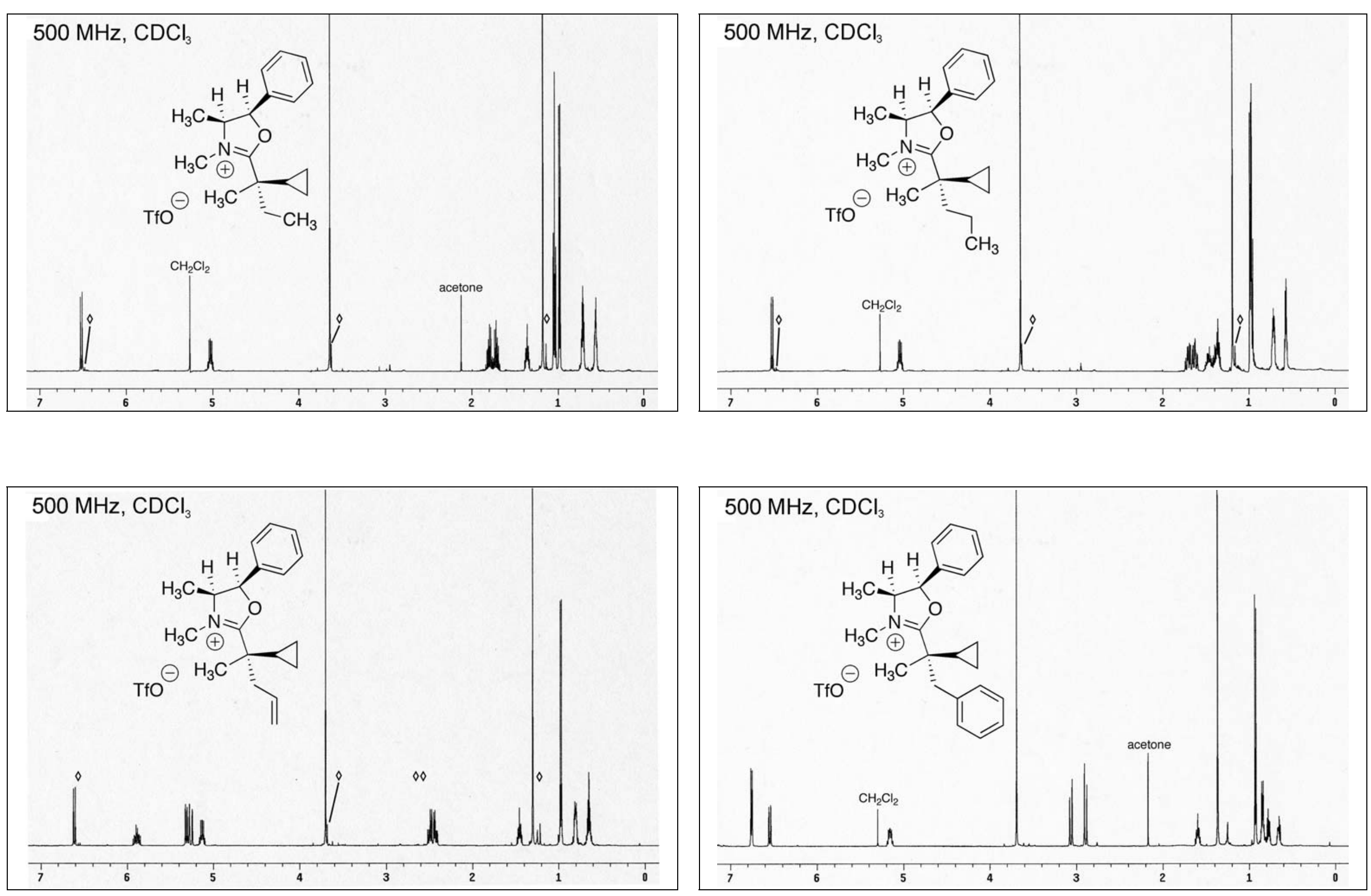

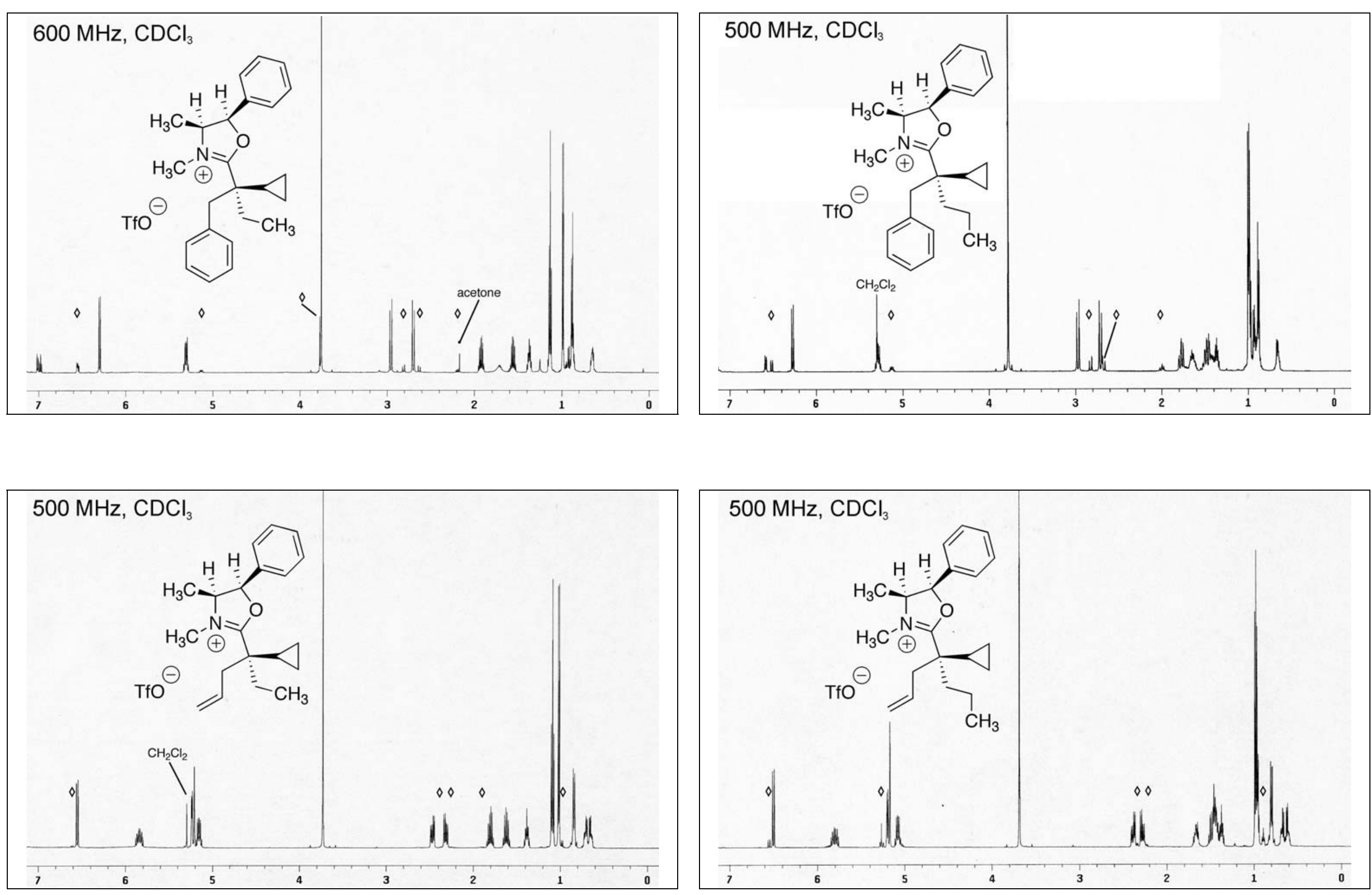

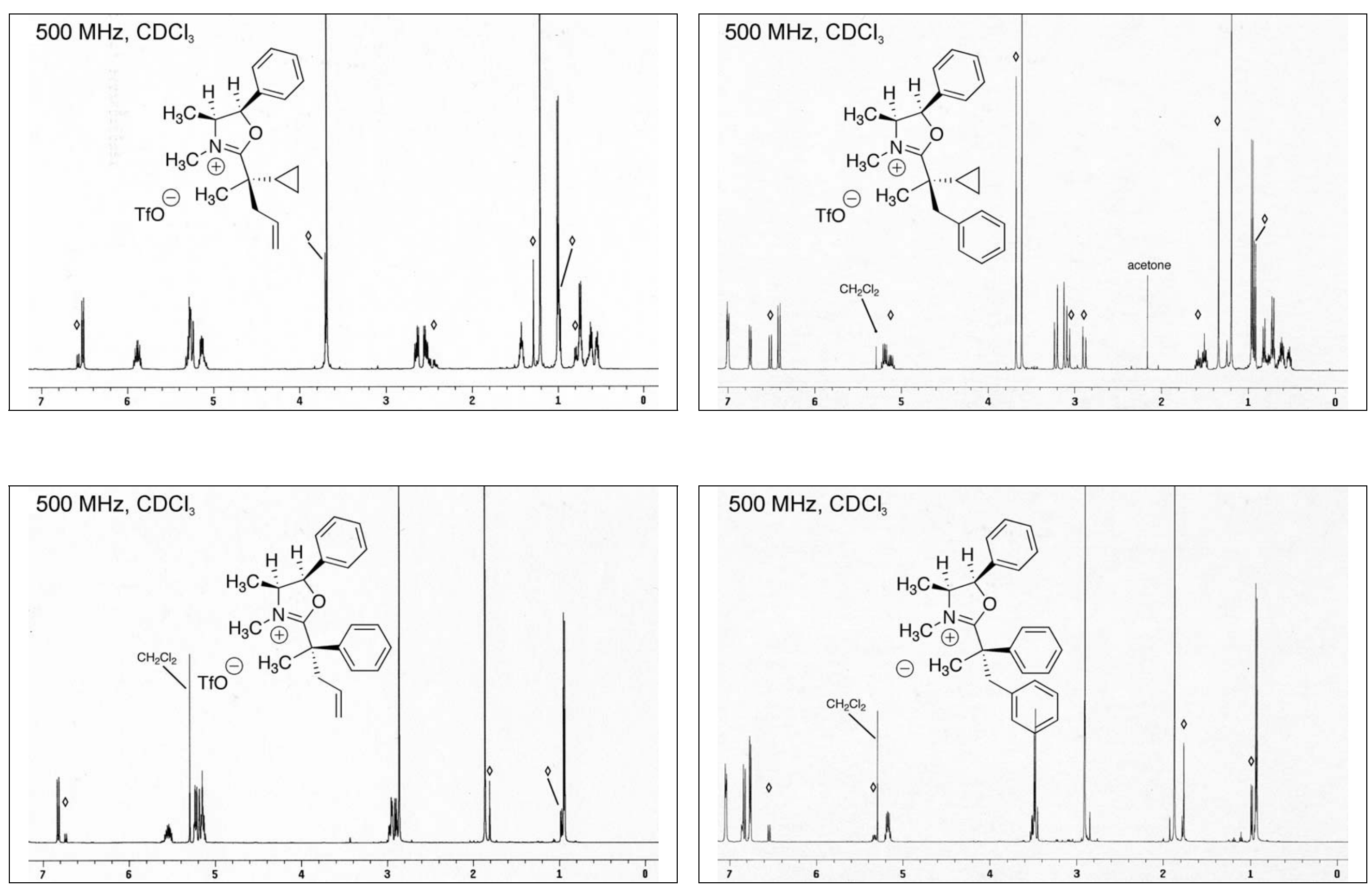

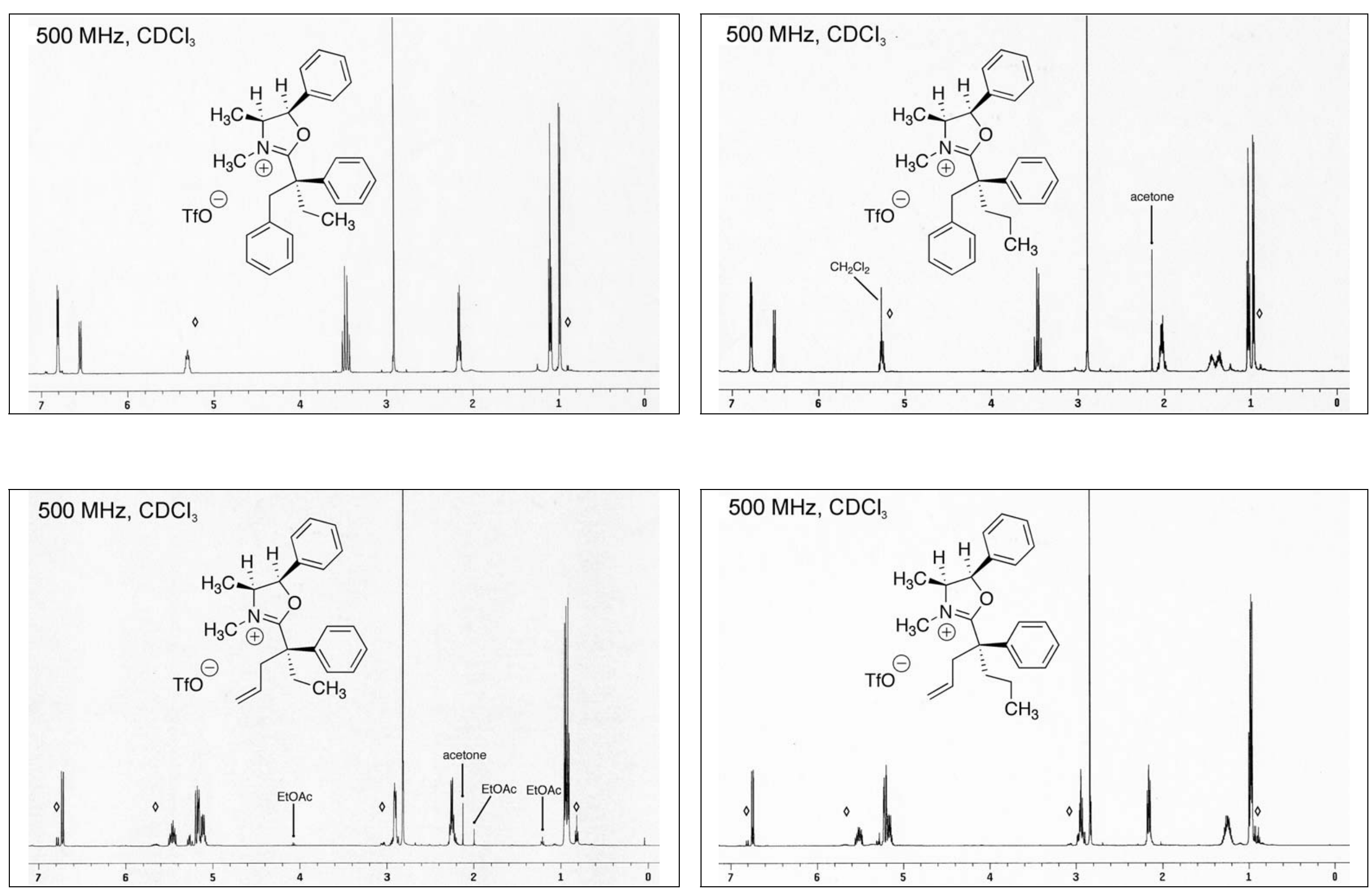

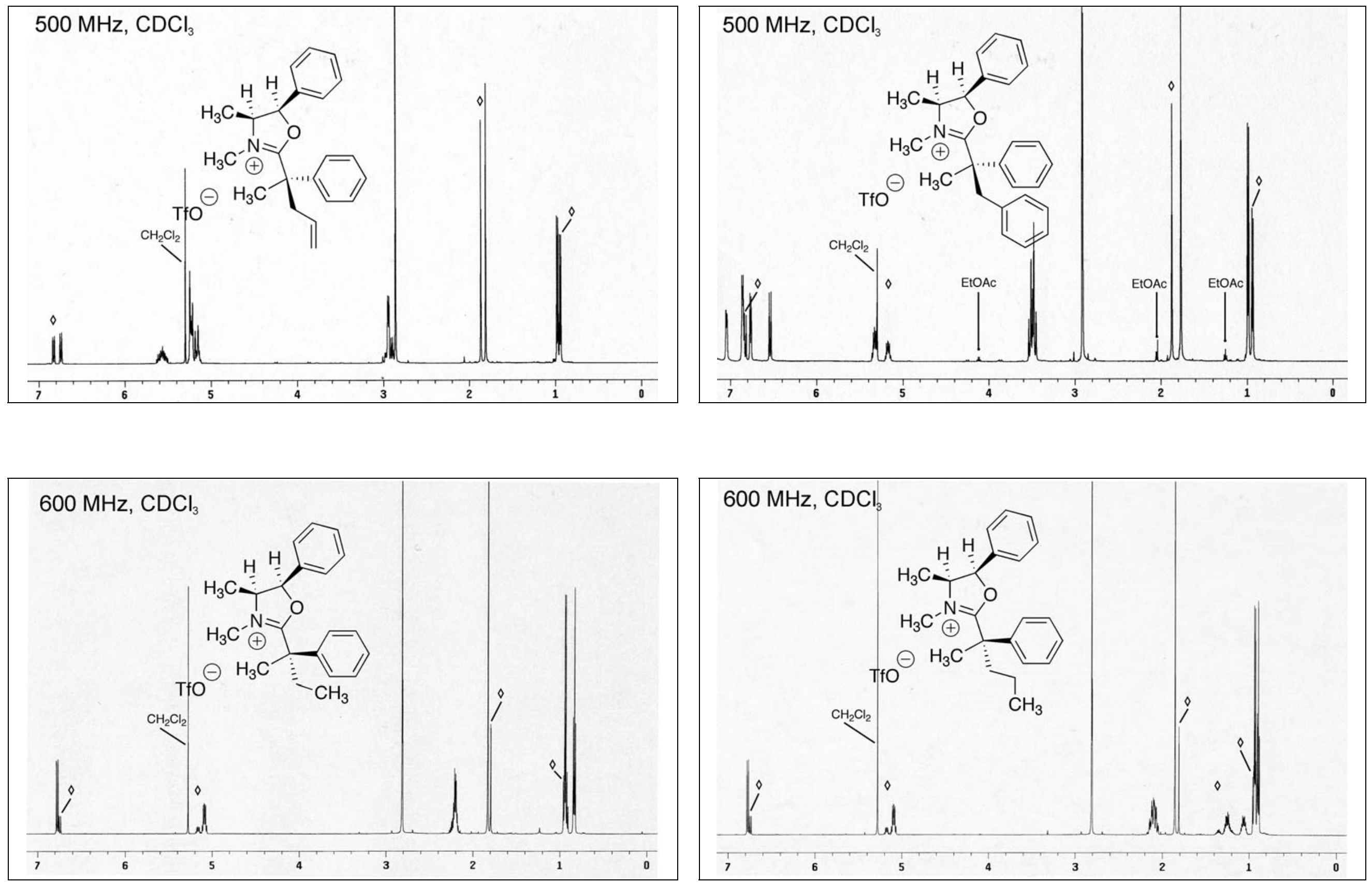

S10 

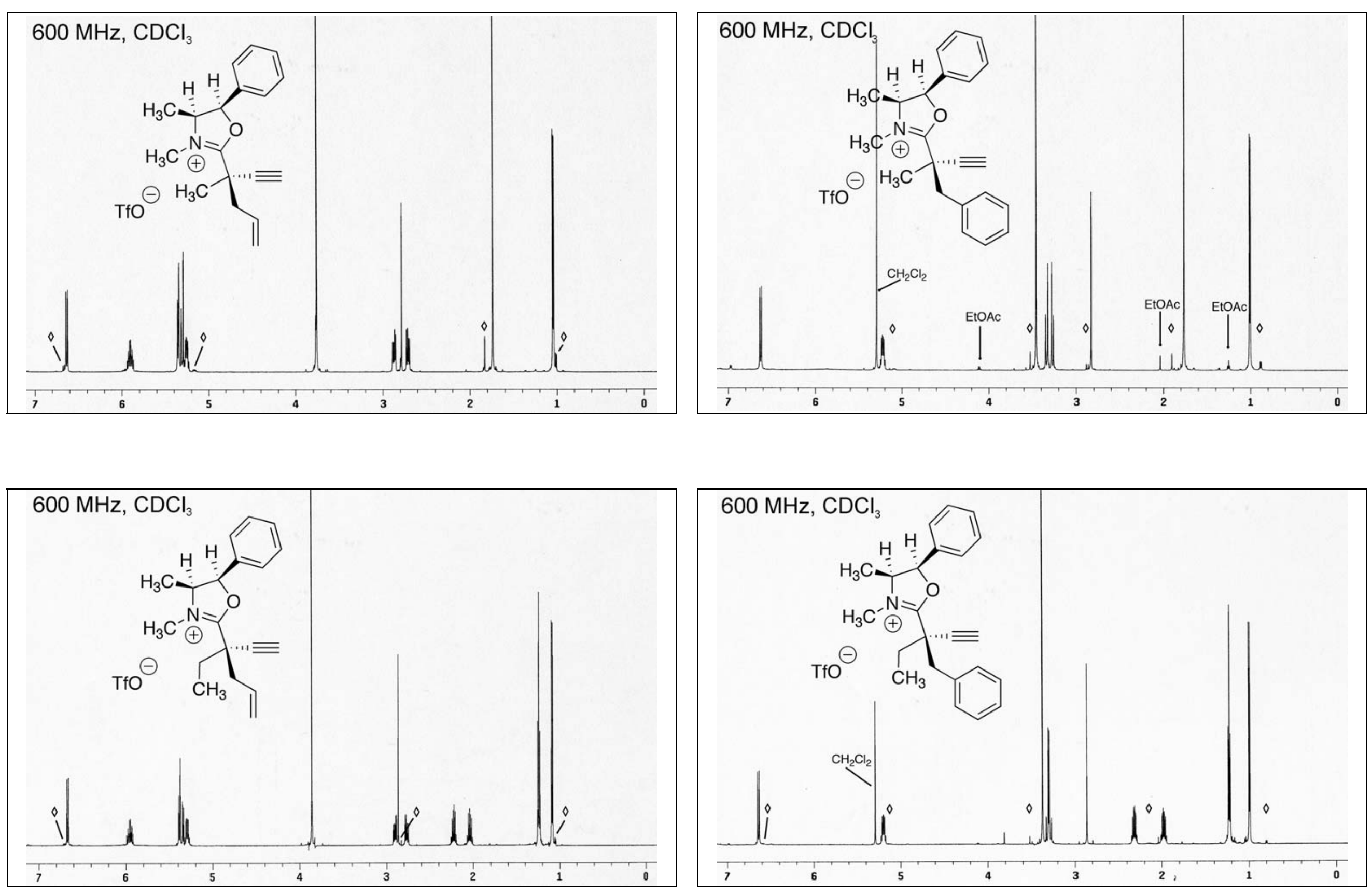

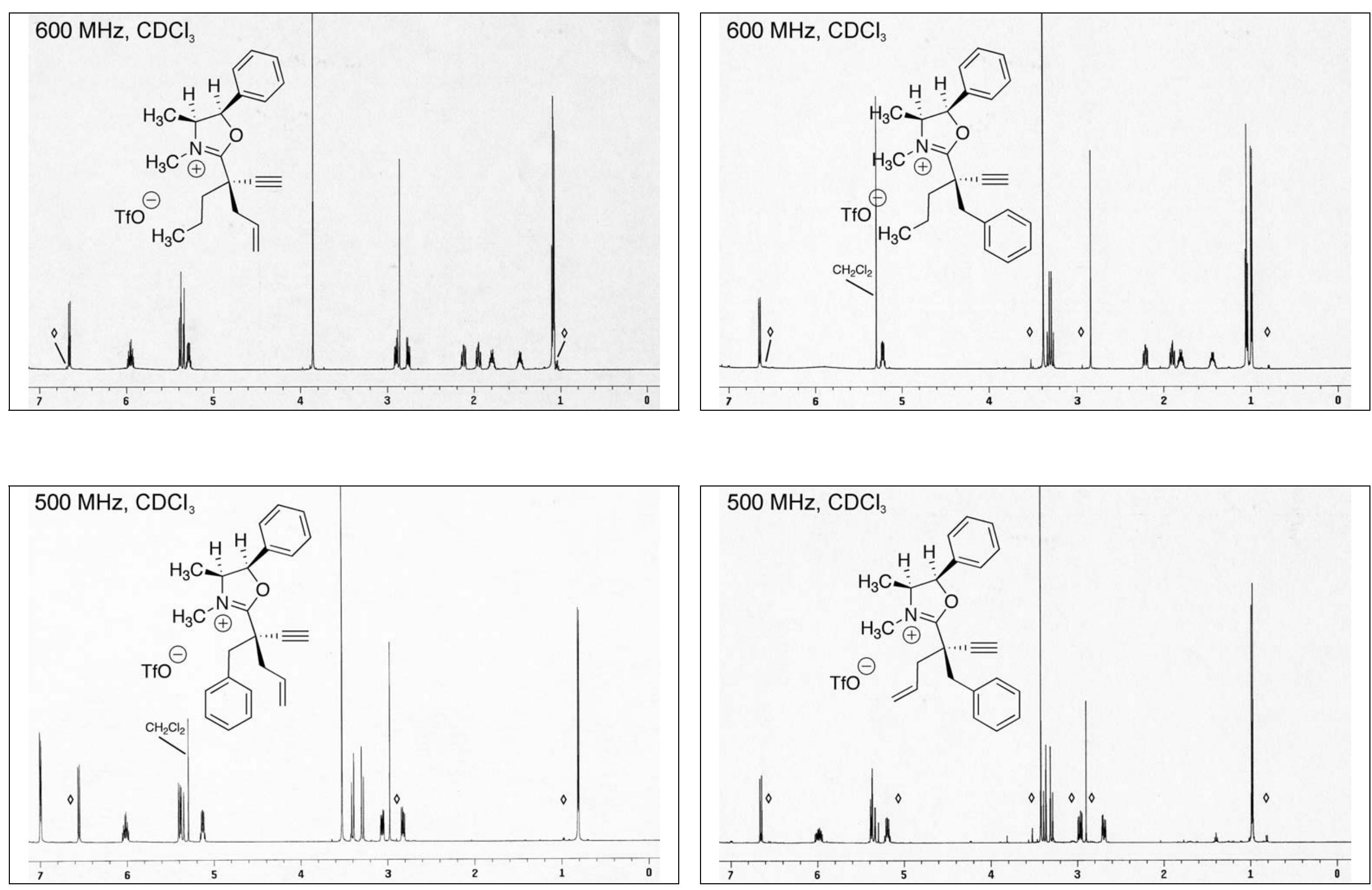


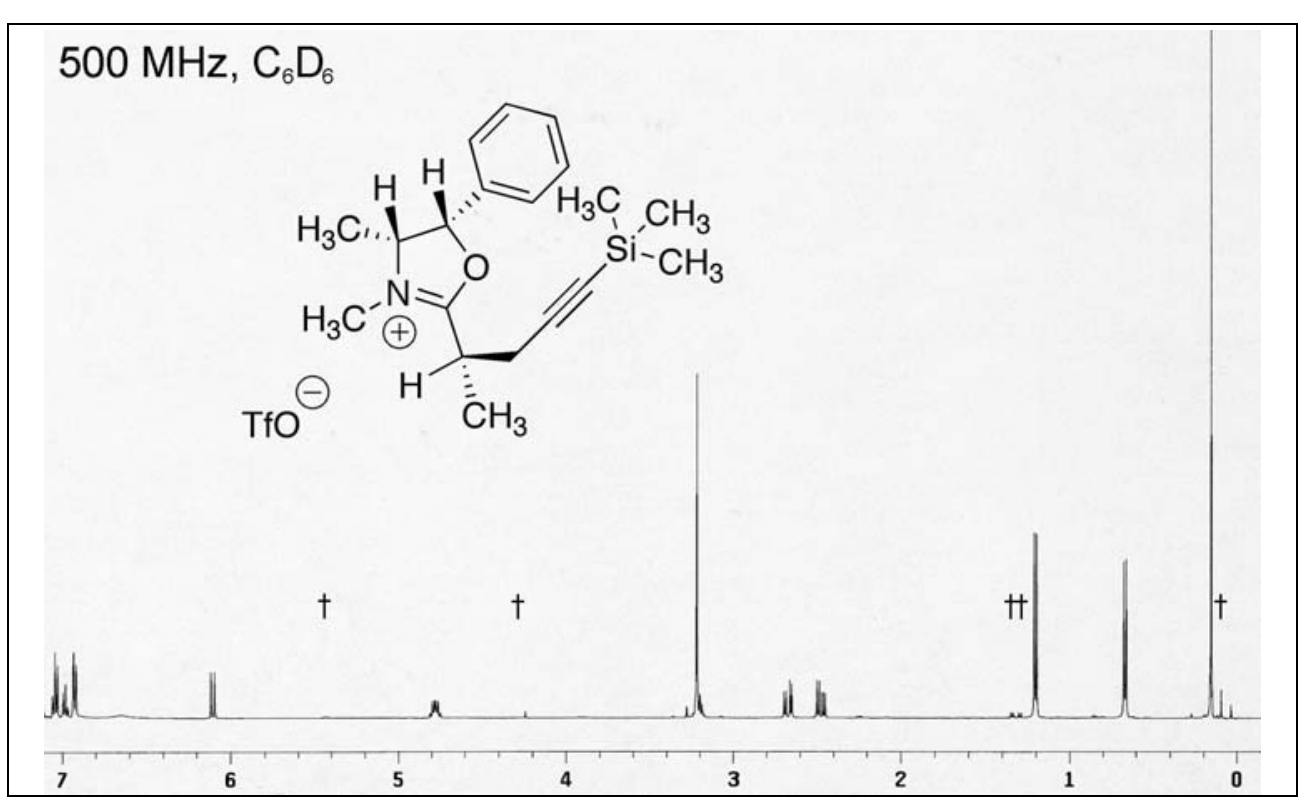

We gratefully acknowledge Mr. Christopher Coletta (Harvard University) for the preparation of the compound shown above.

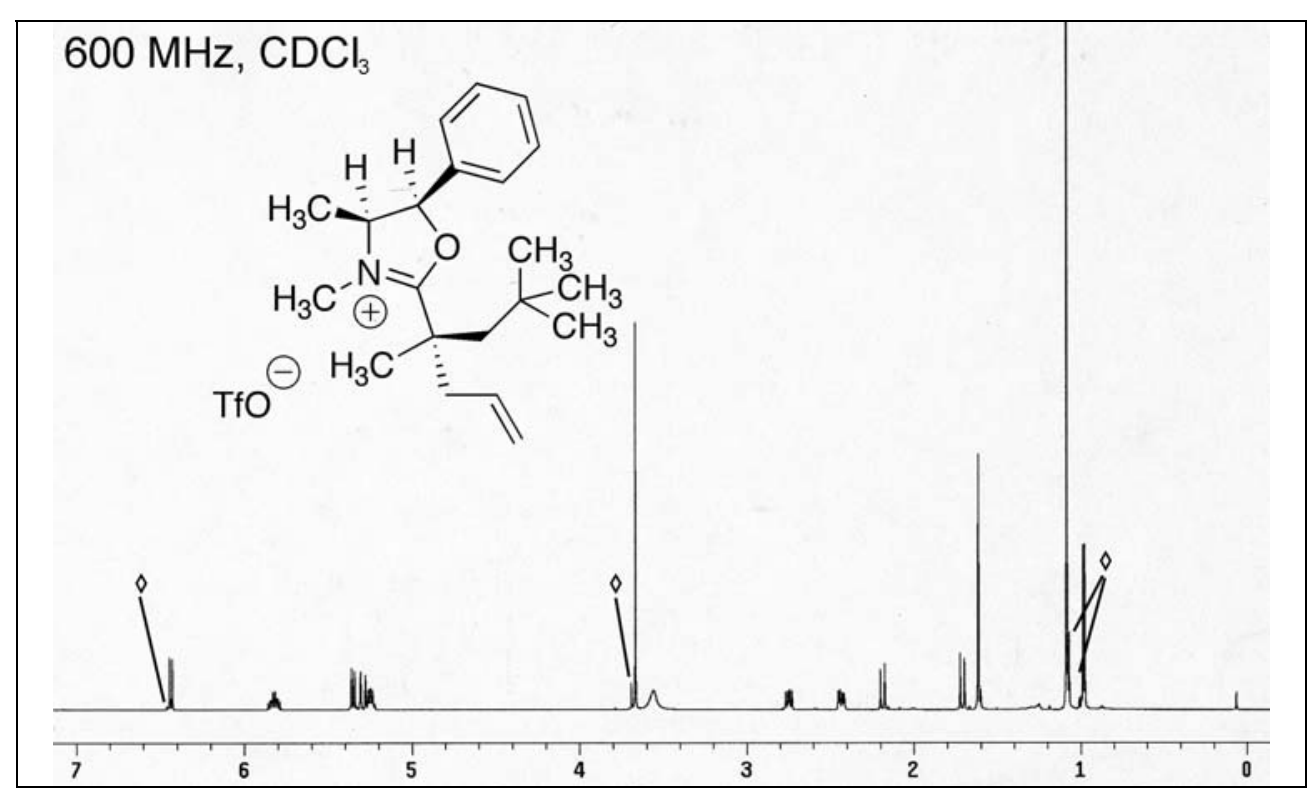

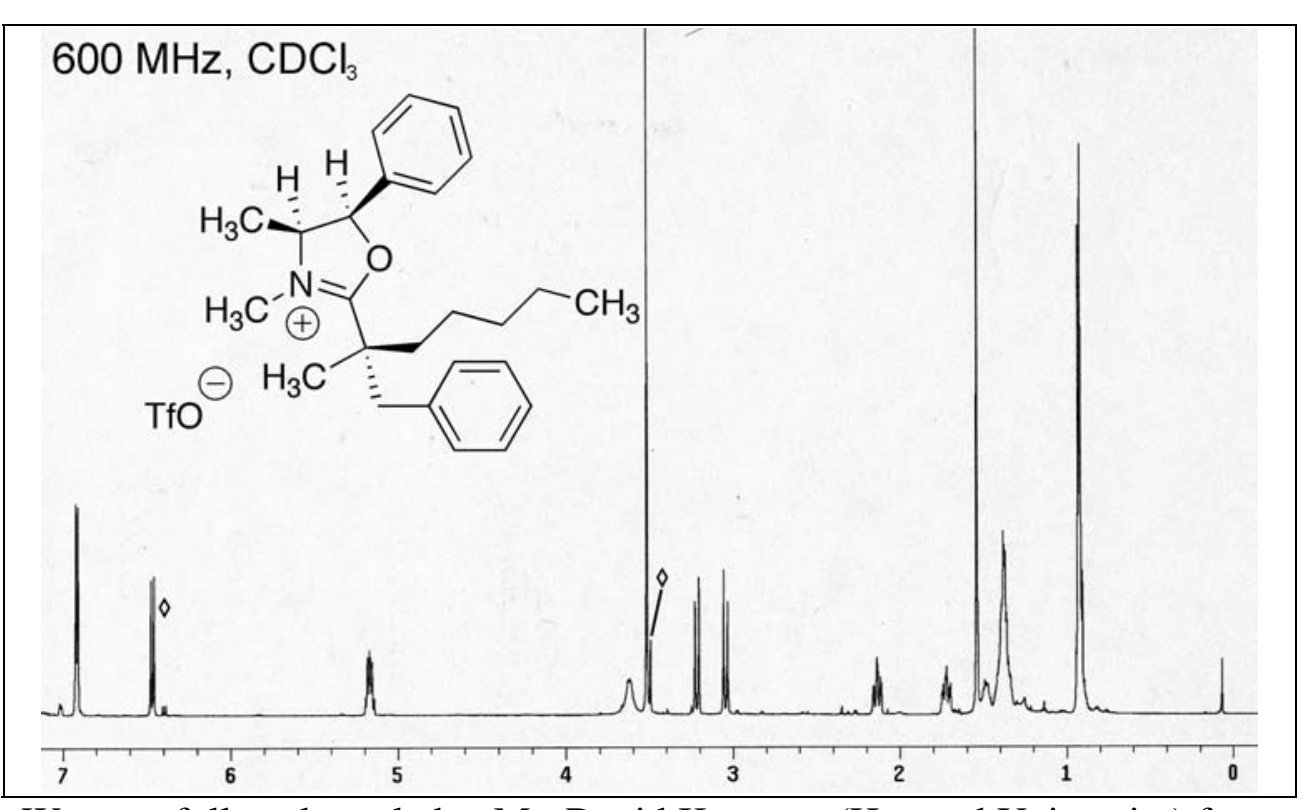

We gratefully acknowledge Mr. David Kummer (Harvard University) for the preparation of the compounds shown above and below.

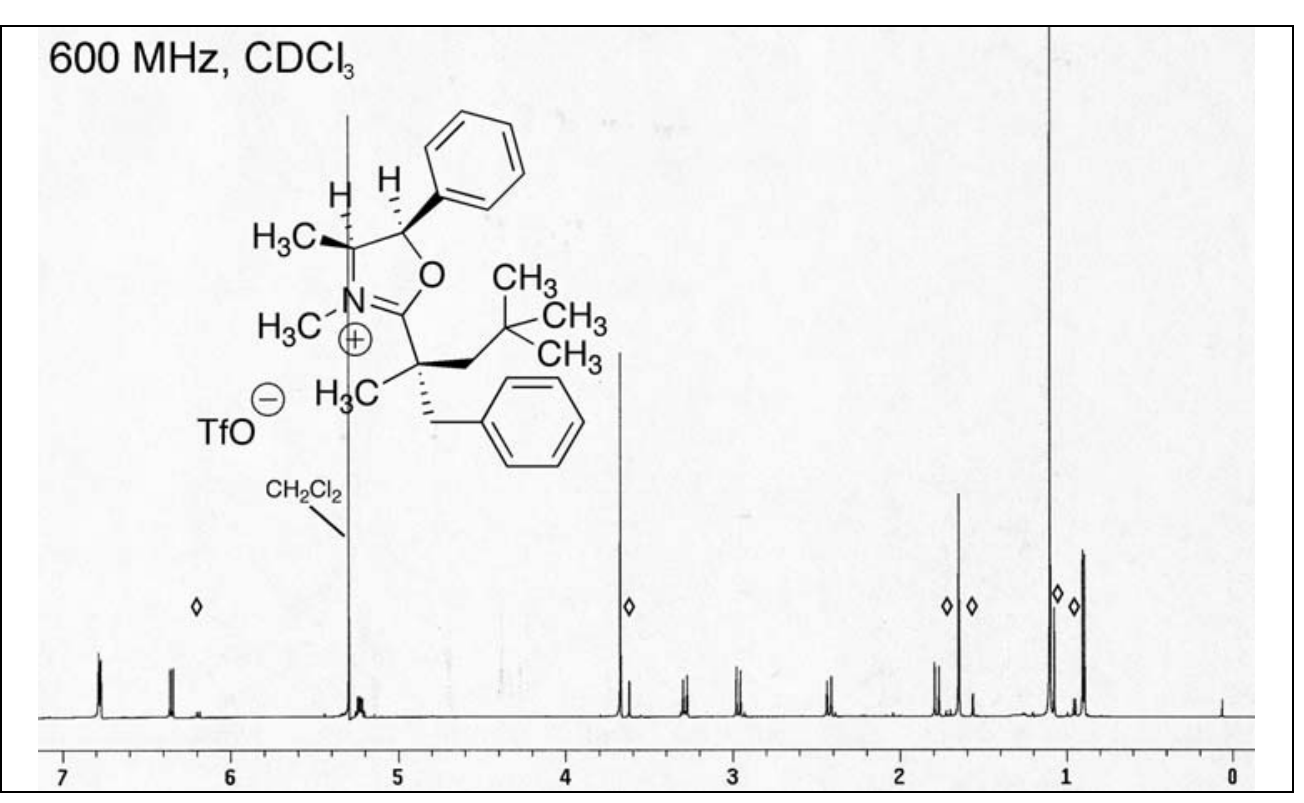



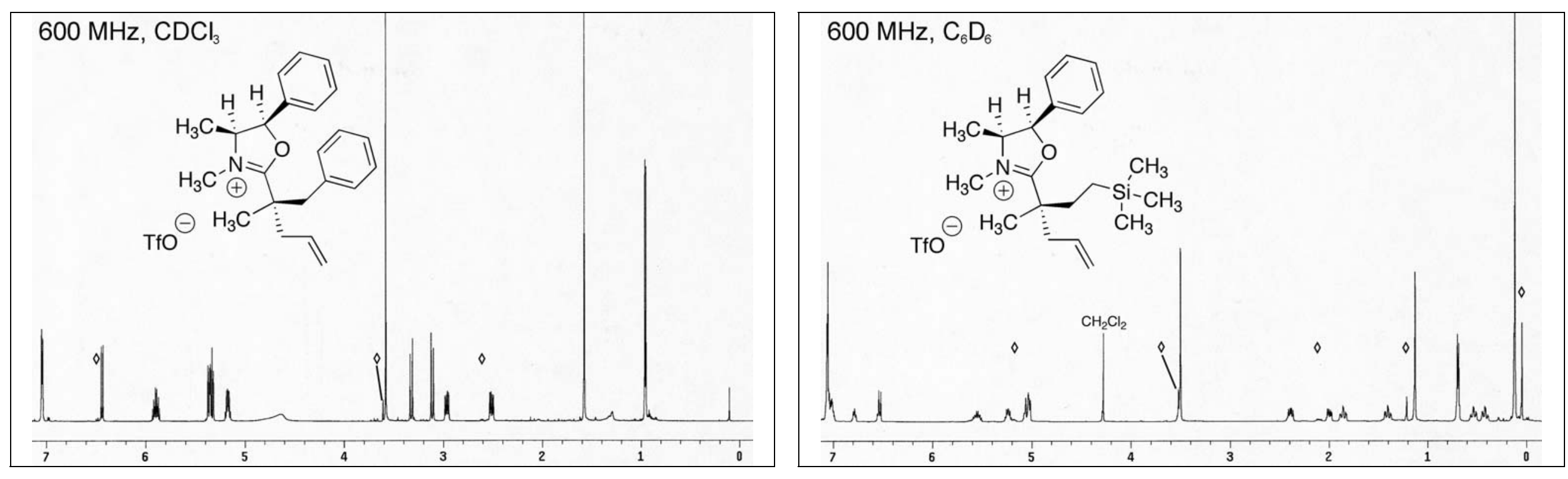

We gratefully acknowledge Mr. David Kummer (Harvard University) for the preparation of the compounds shown above and below.
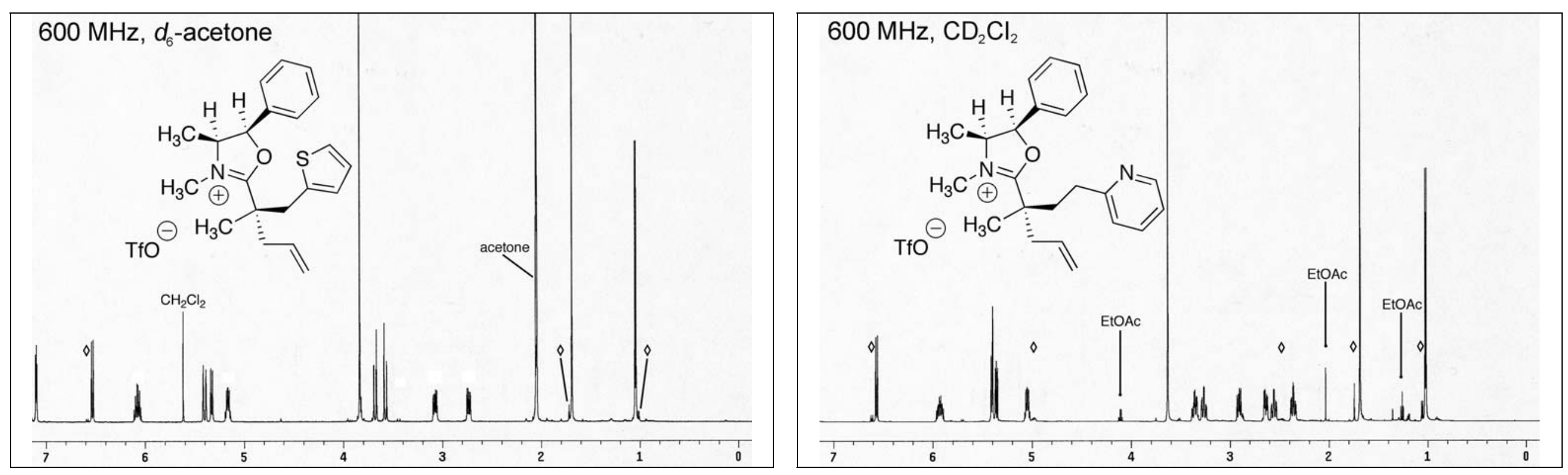